\title{
Morphological and biomolecular characteristics of subcentimetric invasive breast carcinomas in Sicily: A multicentre retrospective study in relation to trastuzumab treatment
}

\author{
A. IENI ${ }^{1}$, G. GIUFFRÈ ${ }^{1}$, S. LANZAFAME ${ }^{2}$, G. NUCIFORO ${ }^{3}$, M. CURDUMAN ${ }^{3}$, L. VILLARI ${ }^{4}$, E. ROZ $^{5}$, G. CERTO ${ }^{6}$,

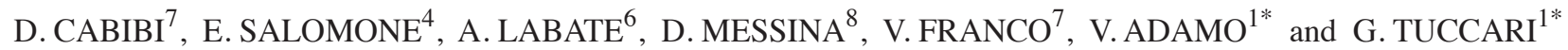 \\ ON BEHALF OF THE SICILIAN SECTIONS SIAPEC-IAP-AIOM
}

\author{
${ }^{1}$ Department of Human Pathology, University of Messina, A.O.U. Polyclinic G. Martino, Messina; \\ ${ }^{2}$ Department of Diagnostic-Forensic Pathology and Public Health, University of Catania, Polyclinic G. Rodolico, Catania; \\ ${ }^{3}$ Humanitas Oncology Center, Catania; ${ }^{4}$ A.O.U. Vittorio Emanuele II, Catania; ${ }^{5}$ La Maddalena Oncology Hospital, Palermo; \\ ${ }^{6}$ Cappellani Pathology Division, Messina; ${ }^{7}$ Department of Human Pathology, University of Palermo, \\ A.O.U. Polyclinic Giaccone, Palermo; ${ }^{8}$ Pathology Division, Sant'Antonio Abate Hospital, Trapani, Italy; \\ *Working Group on Molecular Neoplastic Therapy
}

Received May 5, 2011; Accepted August 30, 2011

DOI: $10.3892 / 01.2011 .425$

\begin{abstract}
Little information from clinical trials is available regarding the efficacy of trastuzumab treatment in subcentimetric breast carcinomas (BCs). The aim of this study was to verify the existence of correlations between HER2 and hormone receptor status, Ki67 values, grade, histotype and node involvement in a cohort of pT1a,b BCs from an area not widely covered by screening campaigns. A total of 410 pT1a,b BC formalin-fixed paraffin-embedded samples collected from eight Sicilian Anatomo-Pathological Units (APUs) were classified according to the WHO classification and tumour grading was established. Estrogen and progesterone receptor status, Ki67 labelling index and HER2 status were available. Relationships between immunohistochemical data and clinicopathological characteristics were investigated using the Chi-square test; the cohort was analysed with respect to pT1a and pT1b BC as well as to node status. Ductal infiltrating carcinoma was the prevalent histotype in the pT1a and $\mathrm{pT} 1 \mathrm{~b}$ stages; $\mathrm{G} 2$ was a more common tumour grade, with a range between $64.6 \%$ and $70 \%$ of pT1a and pT1b, respectively. Taking into consideration the lymph node involvement of pT1a,b BC, only $17.1 \%$ cases were node-positive without a relevant difference between pT1a and pT1b. No significant differences between pT1a and pT1b BC cases emerged in relation to Ki67 LI, hormone receptors and HER2 status. T1a,b BC cases were stratified by node involvement and a
\end{abstract}

Correspondence to: Dr Antonio Ieni, Department of Human Pathology, University of Messina, Via Consolare Valeria, Messina 98125, Italy

E-mail: calaienco@hotmail.com

Key words: small size breast cancer, screening campaign, staging, immunohistochemistry significant relationship was observed with grade as well as with HER2 status. A significant relationship for pT1a cases emerged only for tumour grade, while pT1b cases showed a significant correlation exclusively with HER2 status. Our data clearly support the operative guidelines of the National Comprehensive Cancer Network. Therefore, the combined treatment with trastuzumab plus chemotherapy should be administered only to patients with pT1b or larger BCs. In small HER2-positive pT1a or microinvasive BC, this therapy should be considered on a case-by-case basis, considering tumour grade as the first characteristic.

\section{Introduction}

Breast carcinomas $(\mathrm{BC})$ belonging to stage $\mathrm{T} 1$ have been subdivided with respect to their pathological size in pT1a $(<5 \mathrm{~mm})$, pT1b $(>5$ but $<10 \mathrm{~mm})$ and pT1c $(>10$ but $<20$ $\mathrm{mm}$ ) respectively (1). Moreover, the 2005 St. Gallen meeting panel classified node-negative $\mathrm{BC}$ as low-risk according to the following criteria: $\mathrm{pT} \leq 2 \mathrm{~cm}$, grade 1, absence of peritumoral vascular invasion, patient age $>35$ years, HER2-negative $(2,3)$. However, certain panel members viewed pT1a and pT1b tumours with node-negative disease as representing low risk even when of higher grade and/or occurring in patients of younger age (2). There is no overall consensus regarding guidelines for the management of patients with stage T1a,bNOM0 $\mathrm{BC}$ and, consequently, clinical decisions should be taken on a case-by-case basis, accounting for the known prognostic clinico-pathological features.

Trastuzumab is currently considered to be the basis of care for patients with human epidermal growth factor receptor 2 (HER2)-positive BC in either early or advanced cases, as a monotherapy or in combination with various therapies (4). Certain noteworthy studies have indicated that HER2 overexpression/amplification in T1a,bN0M0 BC may be of benefit to 
clinicians in the decision-making process (4-9). On the other hand, randomised trials provided no data on small tumours $(<1 \mathrm{~cm})$ with negative lymph node involvement $(7,10)$. The impact of HER2 overexpression in T1a,bN0M0 BC has been analysed in two reviews to aid clinicians in the decisionmaking process $(5,6)$. In particular, patients with node-negative HER2-positive pT1a,b BC have a low risk of recurrence at 5 years of follow-up, whereas a less favorable disease-free survival (DFS) was associated with HER2 overexpression in patients with hormone receptor-positive pT1a,bN0 tumours (5). Furthermore, patients with HER2-positive pT1a,bN0M0 tumours have a significant risk of relapse and should be considered for systemic anti-HER2 adjuvant therapy (6).

In the present study, we have obtained a cohort of 410 pT1a,b BC in an attempt to verify the existence of certain associations between HER2 status, hormone receptor status, Ki67 values, grade, histotype and node involvement in Sicilian BC patients. In this geographical area, mammographic screening was introduced in 2000 , but has had a poor coverage generally limited to specific towns and characterised by a low adherence to screening campaigns in comparison to the mean value reported in Italy (11). Finally, the emerging differences in the neoplastic biology observed between pT1a and pT1b were analysed in order to clarify whether treatment with trastuzumab plus chemotherapy should be limited only to T1b or larger cancer, as currently proposed in the National Comprehensive Cancer Network breast cancer guidelines.

\section{Materials and methods}

Materials. We collected a cohort of 410 consecutive pT1a,b BC cases from eight Sicilian Anatomo-Pathological Units (APUs), obtained from patients who underwent surgery between 2007 and 2009. The neoplastic samples were gross-measured in three dimensions and the largest diameter measured was considered to be the invasive component. Tissue fragments were $10 \%$ neutral formalin-fixed for $24-48 \mathrm{~h}$ at room temperature and paraffin-embedded at $56^{\circ} \mathrm{C}$. On $4-5-\mu \mathrm{m}$ haematoxylin-eosinstained sections, tumours were classified according to the WHO histological classification of breast tumours, as modified by Rosen and Obermann (12), while tumour grading was established according to Elston and Ellis (13).

Methods. For each case, estrogen (ER) and progesterone receptor (PR) status and Ki67 labelling index (determined by MIB-1 monoclonal antibody), were available. The threshold for ER and PR positivity was $>10 \%$, whereas Ki67 overexpression was registered when the median value of $13 \%$ was considered as a cut-off. To evaluate the inter-observer agreement, a set of 100 immunostained sections was independently re-evaluated by two expert pathologists (G.N. and G.T.): a favourable correlation and reproducibility was obtained utilizing kappa statistics. HER2 immunohistochemistry (ICH) expression was evaluated using a 1:400 dilution of a polyclonal antiserum (code A0485; Dako, Glostrup, Denmark).

Scores. IHC expression was scored by two pathologists as follows: 0 , no staining or faint membrane staining; $1+$, faint membrane staining in $>10 \%$ of tumour cells, incomplete membrane staining; $2+$, weak to moderate membrane staining in $>10 \%$ of tumour cells; and $3+$, intense circumferential membrane staining in $>10 \%$ of tumour cells. For this analysis, HER2 scores of 0 and 1+ were considered negative. HER2 IHC 3+ and fluorescent in situ hybridization (FISH)-amplified tumours were considered positive. IHC 2+ tumours and indeterminate tumours were tested for gene amplification by FISH (Vysis Path Vision; Abbott, Chicago, IL, USA). Slides were hybridised with probes to LSI HER2/neu and CEP17 with the Path Vysion HER-2 DNA Probe Kit (Abbott) according to the manufacturer's instructions. Sections were visualised on a fluorescent microscope. Scoring was performed by two pathologists according to the manufacturer's guidelines, and the HER2to-CEP17 ratio was calculated. A HER2-to-CEP17 ratio of two or greater was considered evidence of gene amplification.

Statistical analysis. The possible correlations between immunohistochemical data and clinico-pathological characteristics of pT1a,b BC were investigated using non-parametric methods (Chi-square test). In particular, we analysed the complete cohort in respect to pT1a and pT1b BC as well as to node status. Furthermore, each subgroup (pT1a, pT1b) was examined in relation to pathological and biomolecular parameters between node negative or positive cases. $\mathrm{P}<0.05$ was considered statistically significant. Statistical analysis was carried out using the SPSS package (SPSS Inc., Chicago, IL, USA).

\section{Results}

In our casuistry, the incidence rate of pT1a,b was $11.3 \%$ of all $\mathrm{BC}$ encountered and histopathologically analysed in Sicilian pathological units, with a prevalence of pT1b cases $(72.4 \%)$. Regarding the histotype, the majority of our subcentimetric $\mathrm{BC}$ was represented by ductal infiltrating carcinomas $(80 \%)$, with an equivalent incidence in pT1a (75.2\%) and pT1b $(81.8 \%)$ cases. Moreover, the most widely represented tumour grade was G2 $(68.5 \%)$, with a range between 64.6 and $70 \%$ of pT1a and pT1b, respectively. These parameters exhibited a clearly significant P-value. Taking into consideration the lymph node involvement of pT1a,b BC, only $17.1 \%$ cases were node-positive with no significant difference between pT1a (14.2\%) and pT1b (18.2\%).

An adequate immunostaining quality was evident in the samples irrespective of the antibody utilised. No significant differences between pT1a and pT1b BC cases emerged in relation to Ki67 LI, hormone receptors and HER2 status. These data are analytically reported in Table I.

When pT1a,b BC cases were stratified by node involvement, a significant relationship was observed for grade $(\mathrm{P}=0.011)$ as well as HER2 status $(\mathrm{P}=0.003)$ (Table II). The analysis of each subgroup revealed a significant relationship for pT1a cases only for tumour grade $(\mathrm{P}=0.012)$ (Table III), whereas $\mathrm{pT} 1 \mathrm{~b}$ cases exhibited a significant correlation exclusively for HER2 status $(\mathrm{P}=0.002)$ (Table IV).

\section{Discussion}

It has been established that increased expression of HER2 oncoprotein or its corresponding gene amplification have been associated with an aggressive phenotype of $\mathrm{BC}$ in terms of disease-free and overall survival $(6,14)$. Nevertheless, in 
Table I. Clinico-pathological and immunohistochemical data of analyzed cohorts.

\begin{tabular}{|c|c|c|c|c|}
\hline & pT1a,b (\%) & pT1a (\%) & pT1b (\%) & P-value \\
\hline Cases & 410 & $113(27.6)$ & $297(72.4)$ & \\
\hline \multicolumn{5}{|l|}{ Histotype } \\
\hline CDI & $328(80.0)$ & 85 (75.2) & $243(81.8)$ & \multirow{5}{*}{$<0.001$} \\
\hline CLI & $56(13.7)$ & $12(10.6)$ & $44(14.8)$ & \\
\hline CTI & $10(2.4)$ & $6(5.3)$ & $4(1.3)$ & \\
\hline CPI & $10(2.4)$ & $8(7.1)$ & $2(0.7)$ & \\
\hline CMI & $6(1.5)$ & $2(1.8)$ & $4(1.3)$ & \\
\hline \multicolumn{5}{|l|}{ Grade } \\
\hline G1 & $83(20.2)$ & $34(30.1)$ & $49(16.5)$ & \multirow{3}{*}{0.002} \\
\hline $\mathrm{G} 2$ & $281(68.5)$ & 73 (64.6) & $208(70.0)$ & \\
\hline G3 & $46(11.2)$ & $6(5.3)$ & $40(13.5)$ & \\
\hline \multicolumn{5}{|l|}{ Node } \\
\hline No & $340(82.9)$ & 97 (85.8) & $243(81.8)$ & \multirow[t]{2}{*}{ NS } \\
\hline $\mathrm{N}+$ & $70(17.1)$ & $16(14.2)$ & $54(18.2)$ & \\
\hline \multicolumn{5}{|l|}{ Ki67 } \\
\hline Low & $285(69.5)$ & $80(70.8)$ & $205(69.0)$ & \multirow[t]{2}{*}{ NS } \\
\hline High & $125(30.5)$ & $33(29.2)$ & $92(31.0)$ & \\
\hline \multicolumn{5}{|l|}{ ER } \\
\hline Low & $59(14.4)$ & $16(14.2)$ & $43(14.5)$ & \multirow[t]{2}{*}{ NS } \\
\hline High & 351 (85.6) & $97(85.8)$ & $254(85.5)$ & \\
\hline \multicolumn{5}{|l|}{ PR } \\
\hline Low & $103(25.1)$ & $33(29.2)$ & 70 (23.6) & \multirow[t]{2}{*}{ NS } \\
\hline High & 307 (74.9) & $80(70.8)$ & $227(76.4)$ & \\
\hline \multicolumn{5}{|l|}{ HER2 } \\
\hline No-Ampl & $356(86.8)$ & $94(83.2)$ & $262(88.2)$ & \multirow[t]{2}{*}{ NS } \\
\hline Ampl & $54(13.2)$ & $19(16.8)$ & 35 (11.8) & \\
\hline
\end{tabular}

NS, no statistical significance. Ampl, amplification.

clinical practice, the treatment of small BC tumours overexpressing HER2 remains a field in which numerous controversies have been identified. However, the impact of HER2 in tumours $<1 \mathrm{~cm}$ in size requires an adequate examination in relation to the hormone receptor subgroups (15), despite the fact that a recent study has confirmed that patients with HER2-positive BC have a consistent risk of recurrence, irrespective of hormone receptor status (5). Nevertheless, ER/PR status appears to be more valid as a predictor of benefit from adjuvant hormonal therapy than as a prognostic factor in subcentimetric NOMO BC (3).

Due to the utilization of breast screening modalities, such as digital mammography, the number of T1a,b BC diagnoses is increasing and a validation for adjuvant trastuzumab therapy in these small breast lesions is required to avoid the infrequent health risks, including congestive heart failure, also indicated in the subcentimetric BC cohort. The current National Comprehensive Cancer Network breast cancer guidelines have proposed that treatment with trastuzumab plus chemotherapy should generally be limited to patients with $\mathrm{T} 1 \mathrm{~b}$ or larger $\mathrm{BC}$, whereas among patients with $\mathrm{T} 1 \mathrm{a}$ or smaller carcinomas it is less likely that the trade-offs of risk and benefit require chemotherapy plus trastuzumab (7).
Breast screening in Sicily, the most populous Italian region, has only been recently introduced and, generally speaking, still exhibits a poor coverage. In particular, in 2000, the rate of eligible female (age range 50-69 years) residents in areas covered by the screening campaign was limited to $5 \%$; three years later, this percentage achieved $10 \%$ and, in 2006, the most recent epidemiological data available, this rate reached $27.9 \%$ in comparison to the $78.2 \%$ of the Italian mean (16). In Sicily there are only four breast screening programs using mammography, serving the towns of Palermo, Catania, Ragusa and Caltanissetta. In 2005, 45,440 women of 50-69 years of age and in 2006, 64,161 with the same age range were offered screening, obtaining an effective extension of $22 \%$ in comparison to the mean value for Italy of 55\% (16,17). Finally, in 2006, the correct adhesion in Sicily to these breast mammographic screening programs has been $35.6 \%$ in comparison to the Italian mean of $59.6 \%$ (17). However, to date, data concerning subgroups of pT1 breast invasive carcinomas $(a, b, c)$ from this geographical area are not available, since the percentage regarding pT1N0M0 tumours has been referred only for Catania $(28.4 \%)$ and Palermo (29\%) (11). 
Table II. Cases of pT1a,b BC stratified by node involvement.

\begin{tabular}{|c|c|c|c|c|}
\hline & pT1a,b (\%) & N0 (\%) & $\mathrm{N}+(\%)$ & P-value \\
\hline Cases & 410 & $340(82.9)$ & $70(17.1)$ & \\
\hline \multicolumn{5}{|l|}{ Grade } \\
\hline G1 & $83(20.2)$ & $75(22.1)$ & $8(11.4)$ & \multirow{3}{*}{0.011} \\
\hline $\mathrm{G} 2$ & $281(68.5)$ & $233(68.5)$ & $48(68.6)$ & \\
\hline G3 & $46(11.2)$ & $32(9.4)$ & $14(20.0)$ & \\
\hline \multicolumn{5}{|l|}{$\mathrm{Ki}-67$} \\
\hline Low & $285(69.5)$ & $241(70.9)$ & $44(62.9)$ & \multirow[t]{2}{*}{ NS } \\
\hline High & $125(30.5)$ & $99(29.1)$ & $26(37.1)$ & \\
\hline \multicolumn{5}{|l|}{ ER } \\
\hline Low & $59(14.4)$ & $49(14.4)$ & $10(14.3)$ & \multirow[t]{2}{*}{ NS } \\
\hline High & $351(85.6)$ & $291(85.6)$ & $60(85.7)$ & \\
\hline \multicolumn{5}{|l|}{ PR } \\
\hline Low & $103(25.1)$ & $83(24.4)$ & $20(28.6)$ & \multirow[t]{2}{*}{ NS } \\
\hline High & 307 (74.9) & $257(75.6)$ & $50(71.4)$ & \\
\hline \multicolumn{5}{|l|}{ HER 2} \\
\hline No-Ampl & $356(86.8)$ & $303(89.1)$ & $53(75.7)$ & \multirow[t]{2}{*}{0.003} \\
\hline Ampl & $54(13.2)$ & $37(10.9)$ & $17(24.3)$ & \\
\hline
\end{tabular}

NS, no statistical significance. Ampl, amplification.

Table III. Emerging correlations for pT1a cases.

\begin{tabular}{lccc}
\hline & pT1a $(\%)$ & N0 $(\%)$ & N+ (\%) \\
\hline Cases & $113(27.6)$ & $97(85.8)$ & $16(14.2)$ \\
Grade & & & 0 \\
G1 & $34(30.1)$ & $34(35.1)$ & $14(87.5)$ \\
G2 & $73(64.6)$ & $59(60.8)$ & $2(12.5)$ \\
G3 & $6(5.3)$ & $4(4.1)$ & $11(68.8)$ \\
Ki67 & & & $5(31.2)$ \\
Low & $80(70.8)$ & $69(71.1)$ & $1(6.3)$ \\
High & $33(29.2)$ & $28(28.9)$ & $15(93.7)$ \\
ER & & $15(15.5)$ & NS \\
Low & $16(14.2)$ & $82(84.5)$ & $7(43.8)$ \\
High & $97(85.8)$ & & $9(56.2)$ \\
PR & & $26(26.8)$ & NS \\
Low & $33(29.2)$ & $71(73.2)$ & $12(75.0)$ \\
High & $80(70.8)$ & $82(84.5)$ & $4(25.0)$ \\
HER2 & $94(83.2)$ & $15(15.5)$ & NS \\
No-Ampl & $19(16.8)$ & & \\
Ampl & & & \\
\hline
\end{tabular}

NS, no statistical significance. Ampl, amplification.

In the present study, we have retrospectively analysed a cohort of pT1a,b BC consecutively obtained from eight APUs not directly involved in breast cancer screening. Since clinico-pathological as well as biomolecular parameters of these subcentimetric Sicilian BC were available and stan- dardised, we have been able to delineate the correlations between various prognostic parameters. The rate of pT1a,b was $11.3 \%$ of all BC encountered in the above-mentioned Sicilian APUs, which was probably mostly dependent on opportunistic spontaneous mammography coverage occurring 
Table IV. Emerging correlations for $\mathrm{pT} 1 \mathrm{~b}$ cases

\begin{tabular}{|c|c|c|c|c|}
\hline & pT1b & No & $\mathrm{N}+$ & $\mathrm{P}$-value \\
\hline Cases & $297(72.4 \%)$ & $243(81.8 \%)$ & $54(18.2 \%)$ & \\
\hline \multicolumn{5}{|l|}{ Grade } \\
\hline G1 & $49(16.5 \%)$ & $41(16.9 \%)$ & $8(14.8 \%)$ & \multirow{3}{*}{ NS } \\
\hline $\mathrm{G} 2$ & $208(70.0 \%)$ & $173(71.2 \%)$ & $35(64.8 \%)$ & \\
\hline G3 & $40(13.5 \%)$ & $29(11.9 \%)$ & $11(20.4 \%)$ & \\
\hline \multicolumn{5}{|l|}{$\mathrm{Ki}-67$} \\
\hline Low & $205(69.0 \%)$ & $172(70.8 \%)$ & $33(61.1 \%)$ & \multirow[t]{2}{*}{ NS } \\
\hline High & $92(31.0 \%)$ & $71(29.2 \%)$ & $21(38.9 \%)$ & \\
\hline \multicolumn{5}{|l|}{ ER } \\
\hline Low & $43(14.5 \%)$ & $34(14.0 \%)$ & $9(16.7 \%)$ & \multirow[t]{2}{*}{ NS } \\
\hline High & $254(85.5 \%)$ & $209(86.0 \%)$ & $45(83.3 \%)$ & \\
\hline \multicolumn{5}{|l|}{ PR } \\
\hline Low & $70(23.6 \%)$ & $57(23.5 \%)$ & $13(24.1 \%)$ & \multirow[t]{2}{*}{ NS } \\
\hline High & $227(76.4 \%)$ & $186(76.5 \%)$ & $41(75.9 \%)$ & \\
\hline \multicolumn{5}{|l|}{ HER 2} \\
\hline No-Ampl & $262(88.2 \%)$ & $221(90.9 \%)$ & $41(75.9 \%)$ & \multirow[t]{2}{*}{0.002} \\
\hline Ampl & $35(11.8 \%)$ & $22(9.1 \%)$ & $13(24.1 \%)$ & \\
\hline
\end{tabular}

NS, no statistical significance.

at any age. Moreover, a statistically significant difference was found between pT1a and pT1b BC in relation to histotype and tumour grade, regardless of lymph node involvement. On the other hand, no differences were found regarding growth fraction and hormone receptor and HER2 status. In addition, by stratifying pT1a,b cases in relation to node status, a significant association was found between HER2 overexpression and node metastasis as well as histological grade. These data revealed an indirect agreement with data reported in a previous study, in which patients with HER2positive tumours of $1 \mathrm{~cm}$ or smaller exhibited a high risk of relapse and were therefore considered for systemic adjuvant trastuzumab therapy (6). However, when we considered each pT1 subgroup, a statistically significant correlation emerged for HER2 status exclusively in pT1b cases, while the tumour grade appeared to be the most significant parameter in pT1a BC. Although these latter features were retrospectively obtained from a geographical area not widely covered by a systematic BC screening campaign, they clearly support the operative guidelines of the National Comprehensive Cancer Network, which have proposed that combined treatment with trastuzumab plus chemotherapy should be administered only to patients with pT1b or larger BC. In small HER2-positive pT1a or microinvasive $\mathrm{BC}$, the decision to treat these cancers by trastuzumab-chemotherapy combination should be considered on a case-by-case basis, taking the tumour grade into account as the first characteristic as it is one of the most widely acknowledged classical histoprognostic characteristics. From these results it appears that randomised trials to define treatment for small subcentimetric cancer are required, since the low rate of death events as well as casuistries limited to few pT1a,b BC samples have represented a bias for oncologists.

\section{References}

1. Greene FL, Page DL, Fleming ID, Fritz A, Balch CM, Haller DG et al (eds). AJCC cancer staging handbook: TNM classification of malignant tumours. 6th edition. Wiley, New York, 2002.

2. Goldhirsch A, Gelber RD, Viale G, Colleoni M and Coates AS: Prediction of cancer outcome with microarrays. Lancet 365: 1685-1686, 2005.

3. Hanrahan EO, Valero V, Gonzalez-Angulo AM and Hortobagyi GN: Prognosis and management of patients with node-negative invasive breast carcinoma that is $1 \mathrm{~cm}$ or smaller in size (stage 1; T1a,bNOM0): a review of the literature. J Clin Oncol 13: 2113-2122, 2006.

4. Spector NL and Blackwell KL: Understanding the mechanisms behind trastuzumab therapy for human epidermal growth factor receptor 2-positive breast cancer. J Clin Oncol 34: 5838-5847, 2009.

5. Curigliano G, Viale G, Bagnardi V, Fumagalli L, Locatelli M, Rotmensz N, Ghisini R, Colleoni M, Munzone E, Veronesi P, Zurrida $\mathrm{S}$, Nolè $\mathrm{F}$ and Goldhirsch $\mathrm{A}$ : Clinical relevance of HER2 overexpression/amplification in patients with small tumor size and node-negative breast cancer. J Clin Oncol 34: 5693-5699, 2009.

6. Gonzalez-Angulo AM, Litton JK, Broglio KR, MericBernstam F, Rakkhit R, Cardoso F, Peintinger F, Hanrahan EO, Sahin A, Guray M, Larsimont D, Feoli F, Stranzl H, Buchholz TA, Valero V, Theriault R, Piccart-Gebhart M, Ravdin PM, Berry DA and Hortobagyi GN: High risk of recurrence for patients with breast cancer who have human epidermal growth factor receptor 2-positive, node-negative tumors $1 \mathrm{~cm}$ or smaller. J Clin Oncol 34: 5700-5706, 2009.

7. Burstein HJ and Winer EP: Refining therapy for human epidermal growth factor receptor 2-positive breast cancer: $\mathrm{T}$ stands for trastuzumab, tumor size, and treatment strategy. J Clin Oncol 34: 5671-5673, 2009.

8. Crivellari D and Molino A: Small tumor size and node-negative HER2-positive breast cancer: a step forward for a better treatment? J Clin Oncol 16: e257, 2010.

9. Curigliano G, Viale G, Bagnardi V, Fumagalli L, Locatelli M, Rotmensz N, Ghisini R, Colleoni M, Munzone E, Veronesi P, Zurrida S, Nolè F and Goldhirsch A: Reply to D. Crivellari et al. J Clin Oncol 16: e258, 2010. 
10. Petrelli F and Barni S: Should adjuvant trastuzumab be offered in very early-stage (pT1a/bNOM0) HER2-neu-positive breast cancer? A current debate. Med Oncol, DOI 10.1007/s12032-0109460-0, 2010.

11. Sciacca S, Sciacchitano S, Fidelbo M, Benedetto G, Madeddu A, Vasquez E, Cordio S, Caltavituro G, Castaing M, Cutello P, Pesce P, Ragusa R, Sciacchitano C, Torrisi A and Torrisi A: Breast neoplasms in the Province of Catania: data from the Integrated Neoplasms Registry, Catania-Messina-Siracusa, 2003-2005. Epidemiol Prev 33: 59-69, 2009.

12. Rosen PP and Oberman H: Tumours of the mammary gland. Washington DC Armed Forces Institute of Pathology 1993.

13. Elston CW and Ellis IO: Pathological prognostic factors in breast cancer. I. The value of histological grade in breast cancer: experience from a large study with long-term follow-up. Histopathology 41: 151-152, 2002.

14. Joensuu H, Isola J, Lundin M, Salminen T, Holli K, Kataja V, Pylkkänen L, Turpeenniemi-Hujanen $\mathrm{T}$, von Smitten $\mathrm{K}$ and Lundin J: Amplification of erbB2 and erbB2 expression are superior to estrogen receptor status as risk factors for distant recurrence in pT1N0M0 breast cancer: a nationwide populationbased study. Clin Cancer Res 3: 923-930, 2003.
15. Chia S, Norris B, Speers C, Cheang M, Gilks B, Gown AM, Huntsman D, Olivotto IA, Nielsen TO and Gelmon K: Human epidermal growth factor receptor 2 overexpression as a prognostic factor in a large tissue microarray series of node-negative breast cancers. J Clin Oncol 35: 5697-5704, 2008.

16. Giordano L, Giorgi D, Piccini P, Ventura L, Stefanini V, Senore C, Paci E and Segnan N: Time trends of process and impact indicators in Italian mammography screening programmes 1996-2004. Epidemiol Prev 31: 21-32, 2007.

17. Giorgi D, Giordano L, Ventura L, Frigerio A, Paci E and Zappa M: Mammography screening in Italy: 2005 survey and 2006 preliminary data. Epidemiol Prev 32: 7-22, 2008. 